\title{
Employer-Sponsored Education Assistance and Graduate Program Choice, Cost, and Finance
}

\author{
Gregory Gilpin ${ }^{1} \cdot$ Michael Kofoed $^{2}$
}

Received: 9 November 2017

(c) This is a U.S. Government work and not under copyright protection in the US; foreign copyright protection may apply 2019

\begin{abstract}
This paper studies the impact of the Economic Growth and Tax Relief Reconciliation Act of 2001 that amended employer-sponsored education assistance (ESEA) fringe benefits from taxable to nontaxable for graduate studies. ESEA is an integral part of graduate education finance and is the dominant non-loan source of student aid. Using difference-in-difference and triple-difference specifications, we empirically evaluate educational outcomes related to graduate education choice, cost, and finance. The empirical results suggest that post-law reform, non-degree graduate students who exercise ESEA benefits are $12.3 \%$ more likely to attend open-admission institutions, $12.5 \%$ less likely to attend in-state, $10.3 \%$ more likely to attend for-profit colleges, and no changes are identified on cost or education debt loads, relative to their pre-law reform peers. As a whole, no differences in program choice are observed for degree-seeking graduate students. Additionally, the estimates suggest that while degree-seeking graduate students applying ESEA attend programs that cost, on average, $\$ 1170$ more, no changes are identified post-law reform (2008 dollars). Furthermore, degree-seeking graduate students that apply ESEA benefits take out, on average, $\$ 1530$ less in student loans, and this declines by an additional $\$ 1474$ post-law reform (2008 dollars). Analysis by graduate program and also by gender and age suggest substantial heterogeneity from graduate program educational outcomes, especially for MBA students.
\end{abstract}

Keywords Admissions · College choice - Employer-sponsored education assistance · Fringe benefits $\cdot$ Graduate education finance $\cdot$ MBA $\cdot$ Open admission

Electronic supplementary material The online version of this article (https://doi.org/10.1007/s1116 2-019-09562-y) contains supplementary material, which is available to authorized users.

Michael Kofoed

michael.kofoed@westpoint.edu

Gregory Gilpin

gregory.gilpin@montana.edu

1 Montana State University, 306 Linfield Hall, P.O. Box 172920, Bozeman, MT 59715-2920, USA

2 United States Military Academy, 607 Cullum Road, West Point, NY 10996, USA 


\section{Introduction}

Graduate education has become increasingly important for U.S. employers and employees alike (Arcidiacono et al. 2008; Hussey 2012). Between 1995 and 1996 and 2007-2008 school years, the number of students enrolled annually in graduate education increased from around two million students to 2.7 million students (IPEDS). The choice to enroll in a graduate program is complex with each prospective student weighing the expected costs and benefits of attending across a set of affordable programs. Many firms identify sufficient benefit of graduate school attendance to finance a portion or all of the cost for their workers through employer-sponsored education assistance (ESEA) programs. This particular fringe benefit is important as it is the dominant source of non-loan student financial aid to pay for graduate education, used by $23.0 \%$ of all graduate students and $42.6 \%$ of all MBA students during 2004-2008 school years. ${ }^{1}$

In 1978, policymakers passed Section 127 of the Internal Revenue Service code that constructed the framework for employers to extend ESEA non-taxable fringe benefits from narrowly defined job-related educational expenses to any higher education expenses. This legislation greatly expanded the eligibility from a select group of specialists to all workers. Section 127 was a temporary tax provision with a 5-year expiration and policymakers have chosen to renew it biennially for 15 years (often retroactively). During the 1995 renewal process, the graduate education provision was removed, and only undergraduate courses qualified for the non-taxable status. During the 2001 renewal, the Economic Growth and Tax Relief Reconciliation Act (EGTRRA) amended provisions within Section 127 to allow employers to provide tax-free ESEA fringe benefits for graduate education and extended the expiration through December 30, 2010. ${ }^{2}$ The amendments to EGTRRA were the largest since its inception and had profound impacts on graduate education finance.

This paper studies how graduate education choice and finance outcomes were impacted by EGTRRA. We study a nationally representative sample of non-doctoral, non-education graduate students provided by the 1995-1996, 1999-2000, 2003-2004, and 2007-2008 waves of the restricted-access National Postsecondary Student Aid Study (NPSAS). ${ }^{3}$ These data contain a rich set of individual and institutional characteristics, students' financial aid package, and amounts of ESEA benefits exercised. The empirical analysis compares graduate students pre- and post-law reform using difference-in-difference and triple-difference specifications to evaluate five educational outcomes: attending an open-admission program, attending in-state, attending a for-profit college, annual out-of-pocket (net) costs, and total annual educational loans. The estimators identify the difference between those that exercise ESEA benefits post-law reform, relative to those that exercise ESEA benefits pre-law reform. Because our data sample is every 4 years, the empirical analysis estimates the longer run impacts of the law reform, rather than immediate impacts. While we perform several robustness and falsification tests providing evidence that support the main results, due to the data limitations making it infeasible to test the parallel trends assumption, changes to outcomes in the post-law reform period may be attributable to other

\footnotetext{
${ }^{1}$ Compared to $16.8 \%$ who use grants, $6.7 \%$ who use graduate fellowships, and $6.2 \%$ who use tuition waivers. The average amounts of ESEA provided are also quite substantial: $\$ 4,142$ for all graduate students and $\$ 5,619$ for MBA students.

2 See Lerman et al. (2004) for a historical overview of employer-sponsored education assistance in the United States.

${ }^{3}$ An analysis of students enrolled in doctoral and education programs is provided in Table A.5.
} 
unobservable influences. The study has substantial value as it provides insight into how students apply ESEA benefits and provides evidence that the rate of ESEA application has increased substantially during the 2004-2008 period. Moreover, it demonstrates substantial heterogeneity in ESEA use by program type and by students' characteristics.

The descriptive statistics suggest that non-doctoral, non-education graduate students who exercise ESEA benefits post-law reform are more likely to attend an open-admission graduate program, less likely to attend in-state, and more likely to attend a for-profit college, relative to their pre-law reform peers. Moreover, these students' annual out-of-pocket cost of attendance is $\$ 316$ more and total annual loans is $\$ 1440$ less than their pre-law peers. ${ }^{4}$ Using regression analysis, the empirical results suggest that post-law reform, nondegree students who exercise ESEA benefits are $12.3 \%$ more likely to attend an openadmission graduate programs, $12.5 \%$ less likely to attend in-state, $10.3 \%$ more likely to attend a for-profit college, and no changes are identified on cost or education debt loads, relative to their pre-law reform peers. Also, while post-BA certificate students who exercise ESEA benefits are $4.1 \%$ more likely to attend for-profit colleges, post-reform ESEA use reduces this to approximately zero. No differences in program choice are observed for degree-seeking graduate students as a whole. The estimates suggest that while degreeseeking graduate students applying ESEA attend programs that cost, on average, $\$ 1170$ more, no changes are identified post-law reform (2008 dollars). Furthermore, degree-seeking graduate students that apply ESEA benefits take out, on average, $\$ 1530$ less in student loans, and this declines by $\$ 1474$ post-law reform (2008 dollars).

Empirical results by gender suggest that post-law reform, non-degree female students increase attendance at open-admission institutions and decrease in-state attendance, relative to males post-law reform. Similarly, post-law reform post-BA certificate male students increased in-state attendance relative to females. Interestingly, post-law reform female MBA students are $13.5 \%$ less likely to attend open-admission programs and $15.3 \%$ less likely to attend for-profit colleges, while male MBA students post reform are $23.2 \%$ more likely to attend an open-admission MBA program and $22.3 \%$ more likely to attend a forprofit college. Female MBA students' net cost remains unchanged, but total annual loans post-law reform fall by $\$ 2,335$. Male MBA students' out-of-pocket costs and total annual loan amounts remain similar post-law reform. Similar results by gender are observed for non-education, non-MBA master's students.

Empirical results by age suggest that older students that use ESEA post-law reform are $17.0 \%$ more likely to attend an open-admission graduate program, 20.2\% less likely to attend in-state, and $12.5 \%$ more likely to attend for-profit colleges. However, no differences in net cost or total annual loans is observed. The results by graduate program suggest that the differences observed by age are almost entirely attributable to non-degree seeking graduate students.

This study contributes to multiple literatures analyzing graduate education choice and finance. First, it adds to the higher education financial aid literature by providing evidence on the dominant non-loan student aid for graduate education (see Cornwell et al. 2006 and Bruce and Carruthers 2014). Second, this paper adds to the labor literature with new estimates of the influence of fringe benefits on human capital investment and education attainment (see Dale-Olsen 2006).

${ }^{4}$ All monetary values in this paper are expressed in 2008 dollars. 


\section{Background}

\section{Section 127}

Employer-sponsored educational assistance programs have been provisioned in Section 127 of the Internal Revenue Service since 1979 (the Revenue Act of 1978). Prior to 1979 , only specific job-related educational expenditures could be excluded from an employee's gross taxable income. When constructing Section 127, policymakers crafted regulation to address three broad policy goals. The first goal was to reduce administrative burden due to tax auditors adjudicating filers' job-related education expense petitions to the IRS. This goal assisted employees, who were no longer required to petition the IRS to decide whether a particular education program qualified, and also lowered administrative costs to employers providing ESEA programs. The second goal was to reduce ambiguity and restrictiveness in the tax code. By relaxing the qualification from only job-related education to any educational program, eligibility increased significantly. The third goal was to remove existing tax code that caused disincentives to upward mobility; due to the broadness of entry-level job descriptions, there are no readily matching job-related educational programs. This made it nearly impossible for these workers to claim educational expense exemptions prior to 1979 , while workers with specialties were more easily able to qualify (see Jones et al. 2010).

For an employer to offer ESEA to their workers under Section 127, it must have a qualified education assistance program. This is defined as a separate written plan that provides educational expense assistance exclusively to employees, and not their spouses or dependents. At the employer's discretion, "employees" may be defined to include persons who have retired, left on disability, or been laid-off. An employer is permitted to impose course completion or grade requirements and to require an employee who exercised ESEA to remain on the payroll for a period of time after program completion or return the ESEA benefits. Employers must provide reasonable notification of the program to employees. ESEA benefits must be coordinated with other tax credits and deductions. Under the law, employers are not required to provide the fringe benefit, but if an employer chooses to do so, the benefit must be offered to all employees in a non-discriminatory basis that does not favor highly compensated employees.

The initial tax law was provisioned for 5 years in 1979 and policymakers renewed the law eight times until EGTRRA of 2001 extended it for 10 years. In 2010, it was renewed again for 2 years and, since, has continually been renewed on a biennial basis. Minor tweaks were made during some of the renewals and these are noted as follows. First, the 1984 and 1986 renewals set tax-deductible ESEA benefit maximums to $\$ 5000$ and $\$ 5250$, respectively. Second, the 1995 renewal provisioned the exclusion of graduate school expenses, immediately requiring ESEA benefits for graduate studies be taxed. Third, the EGTRRA of 2001 reinstated the tax exclusion for graduate school expenses and also provided semi-permanency of the provision by extending it 10 years. ${ }^{5}$ Given these two amendments to the provision, EGTRRA was one of the largest tweaks (relative to the previous eight) as it provided a clear signal to employers that the graduate studies portion of ESEA was not going to be temporary and firms could recover the costs of establishing ESEA

5 See Jones et al. (2010) for background information and law statutes proposed and passed up to 2010. 
programs that included graduate education. Moreover, employees could engage in longer graduate programs without concern of the program ending prior to completion.

The uptake of ESEA programs by employers and employees has been significant. During 2008, the end of our sample period, the National Compensation Survey (2008) estimates $50 \%$ of all workers were offered ESEA benefits, while $78-85 \%$ of all business and financial services management workers were offered ESEA benefits. The number of workers exercising ESEA benefits has also been substantial. In 1993-1994, 431,500 students exercised ESEA benefits and this increased to 913,100 students during 2007-2008, with approximately half enrolling in graduate studies (Jones et al. 2010). This translates into $6.0 \%$ of undergraduate students and $13.4 \%$ of graduate students using ESEA benefits during the $1996-00$ period and use increased to $8.1 \%$ and $21.4 \%$, respectively, during the 2004-2008 period. The average ESEA benefits during 1996-2000 was \$1503 for undergraduates and $\$ 3837$ for graduate students (in 2008 dollars). This increased to $\$ 2317$ for undergraduates and $\$ 4142$ for graduate students during the 2007-2008 school year (authors' calculations using NPSAS). Moreover, the Joint Committee on Taxation estimates that the annual forgone tax revenue attributable to ESEA to be $\$ 0.8$ billion annually in fiscal year 2007 and 2008 (Joint Committee on Taxation 2007). The average annual employment earnings of those that exercise ESEA benefits is \$42,711 for the 2007-2008 academic year (in 2008 dollars), well below the average earnings of full-time, year-round employee of \$50,233 (U.S. Census), and suggesting that firms are adhering to IRS code to not favor highly compensated employees. We are unaware of any data that permit the calculation of the proportion of workers who have ESEA fringe benefits and forgo ESEA benefits while attending an educational program.

\section{Estimates of ESEA Impact on Educational and Occupational Outcomes}

The literature on general human capital formation finds that both firms and workers may stand to benefit from graduate education. First, increased general human capital expands and broadens the firm's stock of competent and productive employees. However, the canonical Becker (1965) model predicts that employees and employers will only invest in graduate education when the marginal benefit of education outweighs the marginal cost. There is a large literature that shows that financial aid (whether employer-sponsored or not) has significant effects on enrollment (Cornwell et al. 2006; van der Klaauw 2002; Dynarski 2003), college and career choice (Avery and Hoxby 2004; Field 2009; Denning and Turley 2017) and completion (Bettinger 2004; Lovenheim and Owens 2014; Denning 2018; Alon 2007).

However, little is known how financial aid affects graduate school choice. Montgomery (2002) estimates a nested logit where individuals are nested by whether they attend full or part time, and then program selection is evaluated. The author finds that blacks and Hispanics are more likely to choose more prestigious programs while women are not. He also finds that students are less likely to go to a school outside of their geographic area and that tuition seems to be inelastic with attendance. Elliott and Soo (2013) find a negative relationship between a program's tuition and fees and the number of applications by estimating a 3SLS model. Bedard and Herman (2008) estimate the probability of attending graduate school given fluctuations in the business cycle and find that during recessions more students are likely to choose graduate school than during expansions. This paper adds to that literature by using a natural experiment using the tax-deductibility of employer-sponsored financial aid on the where an employee chooses to enroll. 
While it may be optimal for the employee to attend graduate school, employers should only offer financial aid if it maximizes profits. One way that ESEA could increase profits is by recruiting and retaining a talented workforce. ${ }^{6}$ Manchester (2010) studies two channels through which ESEA programs may generate positive retention effects. The first is a sorting effect where firms attract individuals with lower discount rates. These workers are both more likely to attend graduate education and less likely to be attracted by outside offers. The second is the participation effect where firms that offer generous fringe benefits are more likely to retain those who participate in the program (Flaherty 2008). The empirical results suggest that $80 \%$ of the program's overall effect on retention comes through sorting. Gicheva (2012) studies MBA program selection and suggests that workers who do not change jobs frequently are more likely to attend MBA programs part-time, and conditional on being part-time, are more likely to exercise ESEA benefits. While the research studies multiple MBA programs, the findings are limited due to omitting $40 \%$ of MBA students who attend open admission MBA programs. In addition, all of the above studies use data from the 1990-1991 school year, prior to the emergence of online, flexible MBA programs.

While research suggests that ESEA benefits should attract the highest quality workers, the relationship between ESEA benefits and graduate program selection has yet to be analyzed in the literature. Moreover, the proliferation of private, for-profit colleges has expanded access to MBA programs. Many of these newly established graduate programs are an attractive alternative due to their open admissions policy and go-at-your-own-pace course scheduling. Other public and private, nonprofit institutions also offer flexible programming (see Mehay and Pema (2010) for an analysis of student enrollment by online ESEA supported classes at the U.S. Naval Postgraduate School.) Despite the private, forprofit education sector expanding rapidly over the last decade, the literature regarding this education sector is sparse. ${ }^{7}$ Given the substantial change in supply of graduate programs, an analysis on workers' graduate program choice over time is warranted; particularly in the light of tax advantages that the government now offers employers who subsidize their employee's graduate education. Our paper builds on this literature by examining graduate program characteristic choice given the policy change that made ESEA tax deductible and increased the probability that a firm would offer their workers ESEA.

\footnotetext{
${ }^{6}$ Neal (1995) suggests firms must balance this education investment with the portability of this capital through worker attrition across firms. This may lead some firms to pay for this increase in capital, but not receive the benefit if the worker moves.

${ }^{7}$ The existing research on private, for-profit colleges is almost exclusively at the undergraduate level. This research finds that private, for-profit colleges are of lesser or equal quality (Deming et al. 2012; Lang and Weinstein 2013; Kinser 2006) and that their students pay higher prices due to these firms price discriminating by setting individual tuition levels based on adjustments to institutionally sponsored aid or federally funded financial aid (Turner 2014; Kofoed 2015; Armona et al. 2018; Cellini et al. 2018). In addition, studying associate's degree students, Gilpin et al. (2015) find that FPCs capture more of the market for education as they are nimbler and change their program offerings and enrollment based on current labor market trends. New field experiments using employment applications that randomly assign institutional credentials to applicants find that firms may have preferences against such applicants (Darolia et al. 2015; Deming et al. 2016).
} 


\section{Data}

\section{Description of Data}

We use a national sample of graduate students from the 199-1996, 1999-2000, 2003-2004 and 2007-2008 waves of the restricted-access National Postsecondary Student Aid Survey (NPSAS). ${ }^{8}$ The National Center of Education Statistics (NCES), a subsidiary of the United States Department of Education, compiles the NPSAS and updates it with a new wave every 4 years. These data contain information from many sources, including admissions records, student interviews, FAFSA, surveys completed by college and university administrators, and personal interviews with students. The NPSAS also draws on institution-level information from IPEDS.

The U.S. federal government requires all institutions that are considered Title IV institutions, defined by their eligibility to offer federal financial aid to their students, to report how they distribute such aid. The NPSAS is a representative sample of Title IV institutions and non-Title IV institutions that voluntarily provide information. ${ }^{9}$ NCES constructs the NPSAS by randomly sampling both institutions and students to create a representation of typical college students for each of the 50 states, the District of Columbia, and Puerto Rico. Each institution of higher education that is eligible for federal student aid (i.e., Title IV compliant) is assigned a sampling probability and sampled with replacement so that the data represent the student body with respect to demographic information, types of financial aid, and majors. We include all graduate students residing in the 50 states and the District of Columbia.

NPSAS identifies the college/university students attend and program characteristics such as the current year in school and whether they are enrolled as non-degree seeking students (both undergraduate and graduate), in a certificate program (both undergraduate and graduate), an associate's, a bachelor's, or a graduate degree. The NPSAS provides students' graduate program by CIP code and also by the following aggregated graduate programs: not in a degree program, post-BA certificate, master's in business administration (MBA), education (any master's), other master's, doctorate program in education (any), professional degree, and other doctorate degree. For the purposes of this research, we reduce the dimensionality of programs by focusing on these larger, aggregate program categories. The data contain student characteristics, such as detailed demographic information, family background, and a measure of income for the students' primary family. Important to this research, the NPSAS contains detailed information about how a student pays for graduate school, including dollar amounts and sources. The NPSAS collects these financial aid variables from institutional financial aid records and student interviews. Our data contain 4430 master's in education students, 15,020 doctoral students, and 16,140 non-doctoral, noneducation graduate students ages 22 to $55 .^{10}$

\footnotetext{
${ }^{8}$ We exclude the 1992-93 and previous waves due to only containing employer aid information for undergraduate students and the 2011-12 wave due to not including any information on employer aid.

${ }^{9}$ One concern of the NPSAS data is that it is not representative of for-profit colleges who do not participate in Title IV. See Cellini and Goldin (2014) and Cellini et al. (2018) for discussion of coverage of institutions within IPEDS. Much of the previous literature using IPEDS data also face this limitation. Deming et al. (2016) suggest that this amounts to measurement error, and as long as the measurement error is uncorrelated with trends in the outcomes of interest, it should only attenuate the estimates.

${ }^{10}$ All observation counts are rounded to the nearest $10 \mathrm{~s}$ as per data license restriction. Results do not change when we include those few students $(\sim 300)$ who are younger than 22 or over 55 and attending graduate school.
} 
There are five educational outcomes analyzed related to graduate program choice, cost, and finance. ${ }^{11}$ First, three program choice variables capture the characteristics of school attended. These indicator variables include whether the student is attending an institution that has an open-admission policy (open admission), that is in their state of residency (attend in-state), and that is attending a for-profit college (attend for-profit college). Second, there are two education cost and finance variables: the total annual loans that the student received during the school year (total loans); and the out-of-pocket cost that a student pays the school defined as total tuition and fees minus total aid (net cost). The aid in the net cost calculation includes institutional aid (that the student does not have to repay), any grants, graduate fellowships, and tuition waivers. Financial aid that obligates the student to provide services to the university, e.g., graduate teaching and research assistantships, are considered employment and excluded from aid, while tuition waivers attached to assistantships are included in the aid calculation. Also, ESEA amounts are excluded from the aid calculation. Lastly, total tuition and fees is not analyzed as the sticker price is often not the amount that students pay out of pocket. ${ }^{12}$

ESEA amounts are solicited during the student interview portion of the data collection process. Because there are no ESEA disclosure mandates on the FAFSA or by federal law, students do not need to disclose employer assistance to institutions. Also, to address privacy concerns, the NPSAS top codes ESEA benefits. The data collection method implies employer assistance amounts may be reported with measurement error. We reduce this error by focusing on the extensive margin whether the student exercises ESEA benefits.

There are important considerations on employer education assistance that are critical to this study. First, workers receive assistance as reimbursement for education-related expenses, rather than the employer remitting payment directly to the institution. By construction, this implies that net cost does not include ESEA amounts. Second, workers may seek to minimize net costs if their employers stipulate that workers are required to repay ESEA benefits if they are not successful in completing their degree or if they do not maintain the required minimum GPA. This concern is not as great for graduate students as they have all earned undergraduate degrees and have demonstrated some academic aptitude. Third, financial aid offices do not observe how much assistance students receive from employers and, thus, their institutional aid decisions are not likely influenced by the amount of ESEA the student applies. This suggests that ESEA may be considered exogenous to institutional decision-making regarding admissions and financial aid. However, it is plausible students disclose this information while communicating with financial aid officers and it is unclear if there is any benefit of doing so as it may result in the reduction in institutional aid.

\footnotetext{
11 The selection of these five educational outcomes is based on the literature. For example, Deming et al. (2016) study the sector and selectivity of institutions on labor market outcomes, Eide et al. (2016) study selectivity and graduate program choice on earnings, while Declercq and Verboven (2018) study admission standards and enrollment and degree completions. Bacolod and Chaudhary (2018) study distance education programs and graduation rates. Armona et al. (2018) study for-profit college attendance and student loan amounts, default rates, and labor market outcomes. While we don't study graduate program choice, see Altonji et al. (2015) for analysis of graduate field choice and the causal effects of education choices on earnings.

12 Analysis of alternative outcomes are provided in Table A.4. The alternative outcomes are total tuition and fees, total grants, graduate fellowships, and tuition waivers.
} 
Table 1 Employer-sponsored tuition assistance use

\begin{tabular}{|c|c|c|c|}
\hline & 1996-2000 & 2004-2008 & Difference \\
\hline \multicolumn{4}{|c|}{ Percent of students exercising employer-sponsored tuition assistance } \\
\hline All graduate & $13.4 \%$ & $21.4 \%$ & $8.0 \%$ \\
\hline Non-degree seeking student & $15.9 \%$ & $24.9 \%$ & $9.0 \%$ \\
\hline Post-BA certificate & $11.6 \%$ & $17.4 \%$ & $5.9 \%$ \\
\hline Masters & $18.1 \%$ & $25.5 \%$ & $7.4 \%$ \\
\hline Business administration & $32.3 \%$ & $42.6 \%$ & $10.3 \%$ \\
\hline Education & $13.0 \%$ & $19.2 \%$ & $6.2 \%$ \\
\hline Other & $13.4 \%$ & $23.2 \%$ & $9.9 \%$ \\
\hline Doctorate & $4.3 \%$ & $10.2 \%$ & $5.9 \%$ \\
\hline Education & $13.4 \%$ & $22.4 \%$ & $8.9 \%$ \\
\hline Professional & $2.4 \%$ & $6.5 \%$ & $4.2 \%$ \\
\hline Other & $4.4 \%$ & $11.5 \%$ & $7.2 \%$ \\
\hline All undergraduate & $6.0 \%$ & $8.1 \%$ & $2.1 \%$ \\
\hline Difference between grad and undergrad & $7.4 \%$ & $13.3 \%$ & $5.9 \%$ \\
\hline \multicolumn{4}{|c|}{ Employer-sponsored tuition assistance amounts ${ }^{\mathrm{a}}$} \\
\hline All graduate & $\$ 3837$ & $\$ 4142$ & $\$ 305$ \\
\hline Non-degree seeking student & $\$ 1078$ & $\$ 1900$ & $\$ 822$ \\
\hline Post-BA certificate & $\$ 2362$ & $\$ 2490$ & $\$ 128$ \\
\hline Masters & $\$ 4264$ & $\$ 4404$ & $\$ 140$ \\
\hline Business administration & $\$ 5664$ & $\$ 5619$ & $-\$ 46$ \\
\hline Education & $\$ 1581$ & $\$ 2771$ & $\$ 1189$ \\
\hline Other & $\$ 3941$ & $\$ 4458$ & $\$ 518$ \\
\hline Doctorate & $\$ 3909$ & $\$ 4814$ & $\$ 905$ \\
\hline Education & $\$ 2911$ & $\$ 3796$ & $\$ 884$ \\
\hline Professional & $\$ 5421$ & $\$ 4516$ & $-\$ 905$ \\
\hline Other & $\$ 3525$ & $\$ 5418$ & $\$ 1893$ \\
\hline All undergraduate & $\$ 1503$ & $\$ 2317$ & $\$ 814$ \\
\hline Difference between grad and undergrad & $\$ 2334$ & $\$ 1825$ & $-\$ 509$ \\
\hline
\end{tabular}

Source: NPSAS 1995-1996, 1999-2000, 2003-2004, and 2007-2008. Sample of higher education students that excludes non-U.S. residences and may exclude some students attending non-Title IV higher education institutions

${ }^{\mathrm{a}}$ Excludes those that did not exercise ESEA benefits

\section{Descriptive Statistics}

Table 1a provides summary statistics of ESEA use between 1996-2000 and 2004-2008 school years for undergraduate and graduate students, and also by graduate program. Overall, $13.4 \%$ of graduate students and $6.0 \%$ of undergraduate students apply ESEA benefits during the 1996-2000 period and use increased by 8.0 and $2.1 \%$, respectively, during the 2004-2008 period. These statistics also suggest that use of ESEA benefits for undergraduate studies is relatively flat and that ESEA benefits applied to graduate studies increased by 5.9\% relative to undergraduate studies during the 2004-2008 period. The increase corresponds to the law reform period when ESEA benefits for graduate 
studies switched from taxable to nontaxable while ESEA benefit for undergraduate studies remained the same.

The data also suggest substantial variation in ESEA use by graduate program. The highest use of ESEA benefits is for master's programs, followed by non-degree seeking students. During 1996-2000, 18.1\% of master's students apply ESEA benefits and this increases to $25.5 \%$ during 2004-2008. Similarly, $15.9 \%$ of non-degree students apply ESEA during 1996-2000 and this increases to 24.9\% during the 2004-2008 period. Interestingly, only $4.3 \%$ and $11.6 \%$ of graduate students exercise ESEA benefits to doctoral programs and post-BA certificates, respectively, during 1996-2000 and these proportions rise to $10.2 \%$ and $17.4 \%$ during $2004-2008 .{ }^{13}$ Within master's programs, $32.3 \%$ of MBA students exercise ESEA benefits during 1996-2000 and this rises to $42.6 \%$ during the 2004-2008 period. This is compared to approximately $13.0 \%$ of master's in education and $13.4 \%$ other master's students during the 1996-2000 period.

As shown in Table 1b, there is significant variation in the amount of ESEA applied, conditional on exercising ESEA benefits. Overall, the average amount of ESEA benefits applied by graduate students is $\$ 3837$ during the 1996-2000 period and $\$ 4142$ during the 2004-2008 period. This is compared to undergraduate students with $\$ 1503$ being applied during the 1996-2000 period and \$2317 during the 2004-2008 period. These differences suggest that ESEA amounts are higher for graduate students relative to undergraduates for both the 1996-2000 and 2004-2008 period. Lower amounts of ESEA is observed for nondegree seeking graduate students and post-BA certificate students in both the 1996-2000 and 2004-2008 periods. Moreover, amounts vary substantially at the master's level with MBA and non-education masters' students applying approximately two to three times the amount of ESEA benefits than master's in education students. At the doctoral level, amounts of ESEA benefits are similar to that of master's students. The data suggest that there is some gravitation towards \$5250 during the 2004-2008 period (the maximum amount of ESEA tax exempt). Due to these differences in rates of use and amounts of ESEA benefits, we conduct analysis for each graduate program category.

The descriptive statistics in Table 1 suggest that students attending doctoral and education programs may be different than non-doctoral, non-education students. There are also structural differences that make these groups of students quite different. First, doctoral students have substantially longer programs, suggesting that these students may have different objectives than non-doctoral graduate students. Second, almost all U.S. public school teachers are compensated based on a salary schedule that explicitly increases teachers' earnings when they earn a master's in education. Due to these differences, we omit the doctoral and education students and focus on non-doctoral, non-education students.

Table 2 provides summary statistics on the five outcomes of interest for all non-doctoral, non-education students. Overall, 9.3\% of non-doctoral, non-education graduate students attend open-admission programs, $80.7 \%$ attend in-state, and 5.5\% attend forprofit colleges. The average net cost, or out-of-pocket cost, is $\$ 2747$ during the sample period, and the average annual total loans is $\$ 5118$. There is also substantial variation in net cost and total loans observed in the data. The majority of the sample are students in master's programs with $20.8 \%$ of students enrolled in an MBA and $57.2 \%$ noneducation, non-MBA master's programs. The remaining students are not enrolled in a

\footnotetext{
13 See Altonji et al. (2015) for analysis of graduate field choice and the casual effects of education choices on earnings.
} 
Table 2 Summary statistics

\begin{tabular}{|c|c|c|c|c|}
\hline & Mean & Std. Dev & Min & $\operatorname{Max}$ \\
\hline \multicolumn{5}{|l|}{ Education outcomes } \\
\hline Open admission & $9.3 \%$ & & 0 & 1 \\
\hline Attend in-state & $80.7 \%$ & & 0 & 1 \\
\hline Attend for-profit college & $5.5 \%$ & & 0 & 1 \\
\hline Net cost & $\$ 2747$ & $\$ 4789$ & $\$ 0$ & $\$ 66,000$ \\
\hline Total loans & $\$ 5118$ & $\$ 9139$ & $\$ 0$ & $\$ 85,198$ \\
\hline \multicolumn{5}{|l|}{ Student characteristics } \\
\hline Not in a degree program & $13.6 \%$ & & 0 & 1 \\
\hline Post-BA certificate & $8.5 \%$ & & 0 & 1 \\
\hline Business administration (MBA) & $20.8 \%$ & & 0 & 1 \\
\hline Other masters & $57.2 \%$ & & 0 & 1 \\
\hline Exercised ESEA: I(ESEA >0) & $23.0 \%$ & & 0 & 1 \\
\hline Outstanding ed. loans & $\$ 8945$ & $\$ 13,911$ & $\$ 0$ & $\$ 154,293$ \\
\hline Full-time worker & $48.2 \%$ & & 0 & 1 \\
\hline Part-time worker & $23.5 \%$ & & 0 & 1 \\
\hline Age & 32.93 & 8.64 & 22 & 55 \\
\hline Married & $43.3 \%$ & & 0 & 1 \\
\hline Family members & 2.16 & 1.41 & 1 & 10 \\
\hline Male & $42.7 \%$ & & 0 & 1 \\
\hline Veteran & $3.9 \%$ & & 0 & 1 \\
\hline Holds graduate degree & $13.6 \%$ & & 0 & 1 \\
\hline Full-time student & $32.4 \%$ & & 0 & 1 \\
\hline White & $74.0 \%$ & & 0 & 1 \\
\hline Black & $10.5 \%$ & & 0 & 1 \\
\hline Hispanic & $6.5 \%$ & & 0 & 1 \\
\hline Asian & $6.5 \%$ & & 0 & 1 \\
\hline Other minority & $2.4 \%$ & & 0 & 1 \\
\hline Observations & 16,140 & & & \\
\hline
\end{tabular}

Sample of non-doctoral, non-education graduate students that excludes non-U.S. residences and may exclude some students attending nonTitle IV higher education institutions. Observation counts rounded to nearest tens as per data license restriction. Standard deviations omitted on indicator variables

program $(13.6 \%)$ or enrolled in post-BA certificate programs (8.5\%). As mentioned previously, $23.0 \%$ of the sample exercise ESEA benefits to attend graduate school.

The table also provides student characteristics in the regression analyses. First, almost half of the sample is married and $42.7 \%$ is male. The equality in gender reflects that graduate students enrolled in education programs are excluded from the sample. Second, the average age of graduate students is 32.9 years, and each has a family with approximately 2.2 individuals. Third, $48.2 \%$ of the sample of students work full time and $23.5 \%$ work part time. Since employment status is highly correlated with earnings, adjusted gross income is excluded from the analysis. Fourth, the sample contains $3.9 \%$ veterans/current military service members. Fifth, $13.6 \%$ of the sample already hold a 
graduate degree and $32.4 \%$ attend school full time. Lastly, the students are composed of $74.0 \%$ white, $10.5 \%$ black, $6.5 \%$ Hispanic, $6.5 \%$ Asian, and $2.4 \%$ other minority. ${ }^{14}$

We provide summary statistics for two important subsamples in Table A.2 Online Appendix. We subsample the data by gender and by age with categories 22-39 and 40-59. The summary statistics suggest that males and females have nearly identical graduate program choice and somewhat different costs and financing. The average net cost to male students is $\$ 3093$ during the sample period, compared to $\$ 2512$ for females. Moreover, average total loans is $\$ 4810$ for males during the sample period, compared to $\$ 5210$ for females. The mean differences by age indicate substantial difference in both education program choice and finance. For example, older graduate students are more likely to attend open admission programs (13.0\% for those age 40-59 vs. $8.2 \%$ for those age $22-39)$, more likely to attend in-state ( $84.5 \%$ for those age $40-59$ vs. $79.5 \%$ for those age $22-39$ ), and more likely to attend for-profit colleges ( $7.3 \%$ for those ages $40-59$ vs. $4.9 \%$ for those ages 22-39). Older graduate students also attend less expensive programs ( $\$ 2463$ for those ages $40-59$ vs. \$2836 for those ages 22-39) and take on substantially less debt (\$3216 for those ages $40-59$ vs. $\$ 5716$ for those ages $22-39$ ). Furthermore, the student characteristics are quite dissimilar. Due to these differences, we conduct additional analysis by gender and age.

\section{Empirical Model}

We first provide a simple framework to understand which groups of workers are impacted by EGTRRA. There are four groups to consider: (A) those working for firms with ESEA programs and use ESEA benefits; (B) those working for firms with ESEA programs, but are not offered ESEA benefits (due to their lower quality worker status or some other reason $)^{15}$; (C) those working for employers who do not offer ESEA benefits; and (D) those working for firms with ESEA programs and are offered ESEA, but choose not to accept the benefit. Due to the number of groups, analyzing the impacts of ESEA benefits is challenging and often researchers seek to reduce the dimensionality of decision-making by eliminating various groups or by exploiting recompositions of these groups due to changes in laws or policies surrounding ESEA eligibility.

In the first approach, researchers structurally model the propensity to exercise ESEA benefits and the outcome of interest using workers of a specific firm/organization using an instrumental variable to address self-selection into ESEA. This approach eliminates

\footnotetext{
14 We provide mean summary statistics across time in Table A.1. These statistics suggest that there are more differences in the outcomes of interest across time than the student characteristics. For example, the percent of students attending open-admission programs doubled, attending for-profit colleges more than doubled, and students' total annual education loan balances almost doubled. This is compared to almost no change in students' attending a particular degree program and in their characteristics such age, being male, being a veteran/active military, being full-time students, and the number of family members. The student characteristics that increased marginally across time are students' outstanding education loan balances, being a full- or part-time worker, holding a graduate degree, and being non-white.

15 As discussed in the background literature, this group was of much concern pre-1979 as firms could only provide ESEA that tied directly back to workers' job descriptions and often general workers' job descriptions did not provide sufficient detail to justify ESEA. This was one of the main justifications by policymakers to establish regulation on ESEA (Sect. 127 of the IRS in 1978) that explicitly requires firms' ESEA programs to not favor highly compensated workers, i.e., firms' ESEA program must be a standard fringe benefit offered to all workers.
} 
groups $\mathrm{B}$ and $\mathrm{C}$ and compares the outcomes of those in groups $\mathrm{A}$ and $\mathrm{D}$. An advantage to this approach is the ability to obtain insight into the mechanisms driving ESEA use. The drawback is the generalizability of results beyond the specific firm/organization. Several researchers have exploited this approach, including Buddin and Kapur (2005).

In the second approach, researchers study the impact of a law/policy that directly changes the value/eligibility of ESEA fringe benefits. The law/policy change causes a recomposition of the groups $\mathrm{B}$ and $\mathrm{C}$ to $\mathrm{A}$ and $\mathrm{D}$ and compares the outcomes of those in groups $\mathrm{A}$ to $\mathrm{C}$ and $\mathrm{D}$. One advantage is that the exogenous shock impacts all individuals in a certain period and causal inference on how workers and firms respond may be identified. Another advantage is that this approach is more generalizable as it analyzes workers across multiple firms/organizations. One drawback is that insight into the mechanism may not be well identified, i.e., the researchers may not observe whether the post-law/policy reform outcomes are attributable to more firms offering ESEA benefits (eligibility) or due to workers being more likely to use ESEA benefits (participation) (Tran and Smith 2017).

In this study, we seek to analyze changes in students' behavior post EGTRRA. Thus, we use the second approach. The baseline empirical specification analyzes students' education choice and finance using a difference-in-difference framework:

$$
\begin{aligned}
y_{i s t}=\alpha_{2} & +\beta_{1} I\left(E S E A_{i s t}>0\right)+\beta_{2} I\left(E S E A_{i s t}>0\right) \times \text { Post }+\beta_{3} X_{i s t}+\beta_{4} X_{i s t} \times \text { Post } \\
& +\beta_{5} \text { Post }+t+\delta_{s}+\delta_{p}+\varepsilon_{i s t}
\end{aligned}
$$

where $y_{i s t}$ is one of the five educational outcomes for student $i$ residing in state $s$ during school year $t$ discussed above. The specification includes a binary variable for the post-law reform period (Post), a host of student characteristics $\left(X_{i s t}\right)$ that are provided in Table 2 and linear time trends, state fixed effects, and graduate program fixed effects (year in school and graduate program indicators). Additionally, we follow Jaeger et al. (2018) that indicate group compositional changes due to the law reform may significantly impact causal interpretation of the treatment effect. They demonstrate that including post-law interactions with student characteristics $\left(X_{i s t} \times\right.$ Post) reduces this concern substantially. We follow the literature and rely on robust standard errors. The difference-in-difference estimator identifies the difference between those that exercise ESEA benefits and those that do not, $\beta_{1}$, and the difference between the pre- and post- law reform, $\beta_{5}$. The coefficient of interest is $\beta_{2}$ and identifies the difference between those that exercise ESEA benefits post-law reform, relative to those that exercise ESEA benefits pre-law reform. Because our data sample is every four years, the empirical analysis is unable to identify immediate impacts, but rather estimates the longer run impacts of the law reform.

One important assumption of the difference-in-difference specification is the parallel trends assumption. Due to the shortness of the panel, we are unable to provide an event study that would provide evidence that this assumption holds. However, we validate assumptions of the difference-in-difference specification in three ways. First, we present evidence on the robustness of the results by incrementally introducing control variables and demonstrating coefficient stability (see Table B.1). We start with a model that only includes the graduate program characteristics, the Post indicator variable, and the $I\left(E S E A_{i s t}>0\right) \times$ Post indicator variable on the right-hand side. We progressively include more variables on the right-hand side and the results from six different models are displayed in the Table B.1 of the Online appendix for all non-doctoral, non-education graduate 
students. ${ }^{16}$ The coefficients' estimates appear quite stable and the largest difference in the impact of ESEA on educational outcomes is, unsurprisingly, when student characteristics are included. Moreover, the results suggest that compositional change post-law reform do not significantly impact causal inference of the law reform. Second, we move the law from 2001 back in time so that the 1999-00 graduate student cohort is impacted by the law erroneously and demonstrate that the law impacts do not happen by chance. This placebo test fortifies the main results. Third, we follow Crump et al. (2009) and Rosenbaum and Rubin (1983) by conducting a propensity score trimming (PST) to exclude those most and least likely to exercise ESEA. This is done by first running a logit on whether a student exercises ESEA using the independent variables in the baseline model (except those related to $I(E S E A>0))$. We then retain only those with estimated propensities between $(0.1$ and 0.9$)$ and estimate Eq. (1). We also conduct the PST analysis for those with estimated propensities between ( 0.2 and 0.8 ). The PST removes those most and least likely to exercise ESEA benefits to reduce dissimilarities between these groups. Lastly, we conduct two different robustness tests by dropping students who are workers at higher education institutions applying tuition waivers and by dropping veterans/active military. All robustness analyses support the main analysis (see Table A.3).

While the above robustness and falsification tests will provide evidence that support the main analysis, due to the data limitations making it infeasible to test the parallel trends assumption, any changes to outcomes in the post-law reform period may be attributable to other unobservable influences that we are unable to identify. The study has substantial value as it provides insight into how students use ESEA benefits and evidence that the rate of ESEA use has increased substantially during the 2004-2008 period. Moreover, it demonstrates substantial heterogeneity by program type and by students' characteristics.

The empirical analysis also studies differences between males and females and between younger students (ages 22-39) and older students (ages 40-55) using a triple-difference framework:

$$
\begin{aligned}
y_{i s t}= & \alpha_{2}+\beta_{1} I\left(E S E A_{i s t}>0\right)+\beta_{2} I\left(E S E A_{i s t}>0\right) \times \text { Post }+\beta_{3} X_{i s t}+\beta_{4} X_{i s t} \times \text { Post } \\
& +\beta_{5} \text { Post }+\beta_{6} I\left(Z_{i s t}\right) \times I\left(E S E A_{i s t}>0\right) \\
& +\beta_{7} I\left(Z_{i s t}\right) \times I\left(E S E A_{i s t}>0\right) \times \text { Post }+t+\delta_{s}+\delta_{p}+\varepsilon_{i s t}
\end{aligned}
$$

where $I\left(Z_{i s t}\right)$ is an indicator variable of 'male' or 'age 22-39'. The coefficients of interest are $\beta_{2}$ that identifies the difference between those that exercise ESEA benefits post-law reform, relative to those that exercise ESEA benefits pre-law reform, and $\beta_{7}$ that identifies the difference between 'males' or 'those ages 22-39' that exercise ESEA benefits postlaw reform, relative to 'males' or 'those ages 22-39' that exercise ESEA benefits pre-law reform. Note that both $I\left(Z_{\text {ist }}\right)$ and $I\left(Z_{i s t}\right) \times$ Post are already included in $X_{i s t}$ and $X_{\text {ist }} \times$ Post.

While our above specifications provide causal inference, the data do not permit the identification of whether post-law changes in ESEA use are attributable to more firms offering ESEA benefits or due to workers being more likely to use ESEA benefits. This limitation is due our sample being at the student level and not the worker level, i.e., the data do not permit us to sort workers between groups $\mathrm{C}$ and $\mathrm{D}$. The descriptive statistics provide some evidence that group $\mathrm{C}$ is smaller than groups $\mathrm{A}$ and $\mathrm{D}$ (see Background section for more information). While we would prefer to also analyze the eligibility versus participation

16 We also include a model with state time trends and show this inclusion does not impact the estimates. 
effects post-law reform, we are unaware of a national panel or repeated cross-section of workers that includes whether their firm offers ESEA and the workers' educational outcomes. However, the above specifications provide important insight into how ESEA benefits impact students' graduate education program outcomes when ESEA non-taxable status is extended to graduate education.

\section{Empirical Results}

\section{Main Results}

The descriptive difference-in-difference statistics for non-doctoral, non-educational graduate students in Table 3 provided evidence that graduate students, in general, have increased attendance at open-admission programs, are slightly less like to attend in-state, and are more likely to attend for-profit colleges between the 1996-2000 and the 2004-2008 periods. There have also been increases in net cost and total annual loans for all graduate students across time. Comparing those that exercise ESEA benefits to those that do not, the data suggest that those that exercise ESEA benefits in the post-law reform period are $1.3 \%$ more likely to attend an open-admission graduate program, $3.2 \%$ less likely to attend instate, and $0.5 \%$ more likely to attend for-profit colleges, relative to their pre-law reform peers. Moreover, these students' annual net cost is $\$ 316$ more and total loans is $\$ 1440$ less than their pre-law peers who exercise ESEA benefits, relative to those that do not exercise ESEA benefits. These statistics provide descriptive evidence to support the hypothesis that ESEA benefits impact students' graduate program choice and finance. With this foundation, we proceed to regression analysis that will control for a host of influences and time trends to estimate the impact of ESEA benefits on students' graduate educational outcomes.

The estimates of Eq. (1) are provided in Table 4 for the five educational outcomes for all non-doctoral, non-education graduate students and also by graduate program. The table only includes the coefficient estimates and standard errors on the main variables of interest: $I\left(E S E A_{i s t}>0\right)$ and $I\left(E S E A_{i s t}>0\right) \times$ Post and the full results are available in Online Appendix B, Table 2.1-2.5. The table also includes the $R^{2}$ from each regression. With five educational outcomes and five different samples of students, Table 4 contains output from 25 regressions. The empirical results suggest that non-doctoral, non-education graduate students that exercise ESEA benefits are 3\% less likely to attend open admission programs, and this declines to zero in the post-law reform period. Additionally, there are no significant differences in rates of attending in-state or attending for-profit colleges between those that exercise ESEA benefits and those that do not in the pre- or post-reform periods. Overall, those that exercise ESEA have higher net costs of $\$ 1195$ and reduce annual loan amounts by $\$ 1715$ relative to those that do not exercise ESEA benefits. The results suggest that those that exercises ESEA benefits post-law reform change their graduate program finances substantially by reducing total annual loans by $\$ 1199$ relative to their pre-law reform peers.

Due to the substantial variation in ESEA use and amounts observed in Table 1, we also provide estimates of Eq. (1) by graduate program. First, non-degree seeking students who exercise ESEA benefits post-reform are $12.3 \%$ more likely to attend open-admission graduate programs, $12.5 \%$ less likely to attend in-state, and 10.3 more likely to attend forprofit colleges, relative to their pre-law reform peers. No impact of ESEA on net cost are identified; however, total annual loans of non-degree seeking students who exercise ESEA 


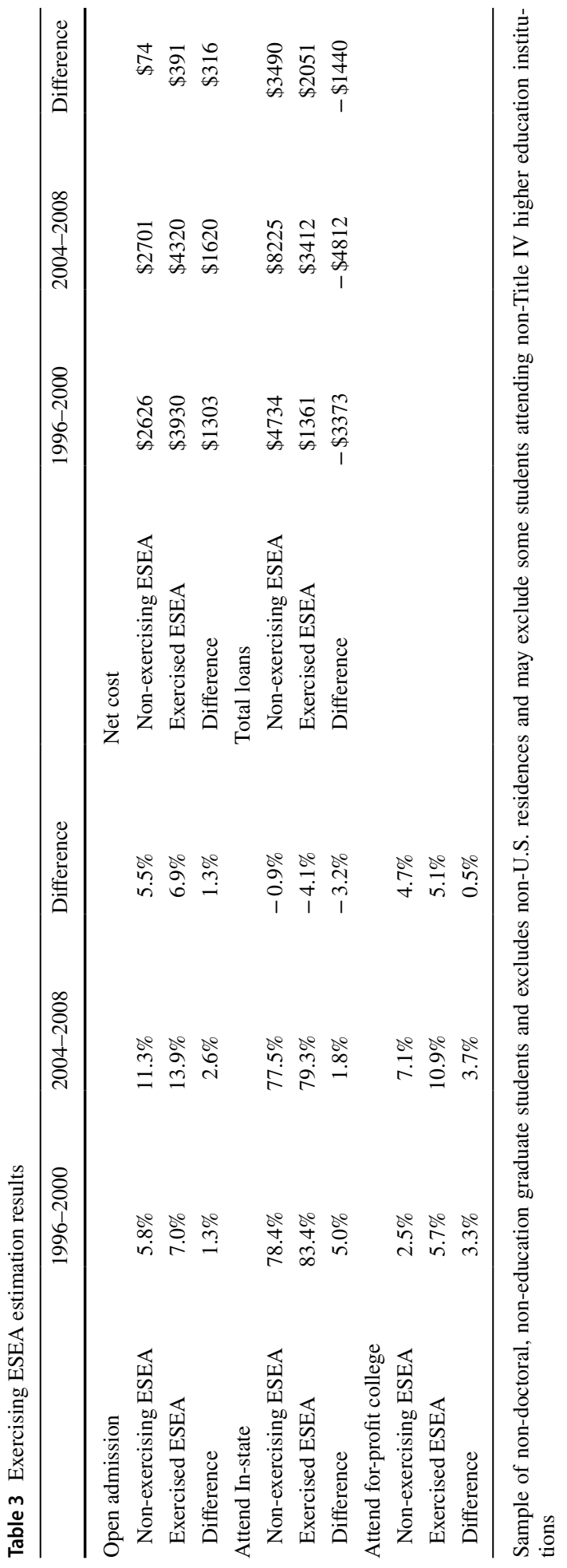




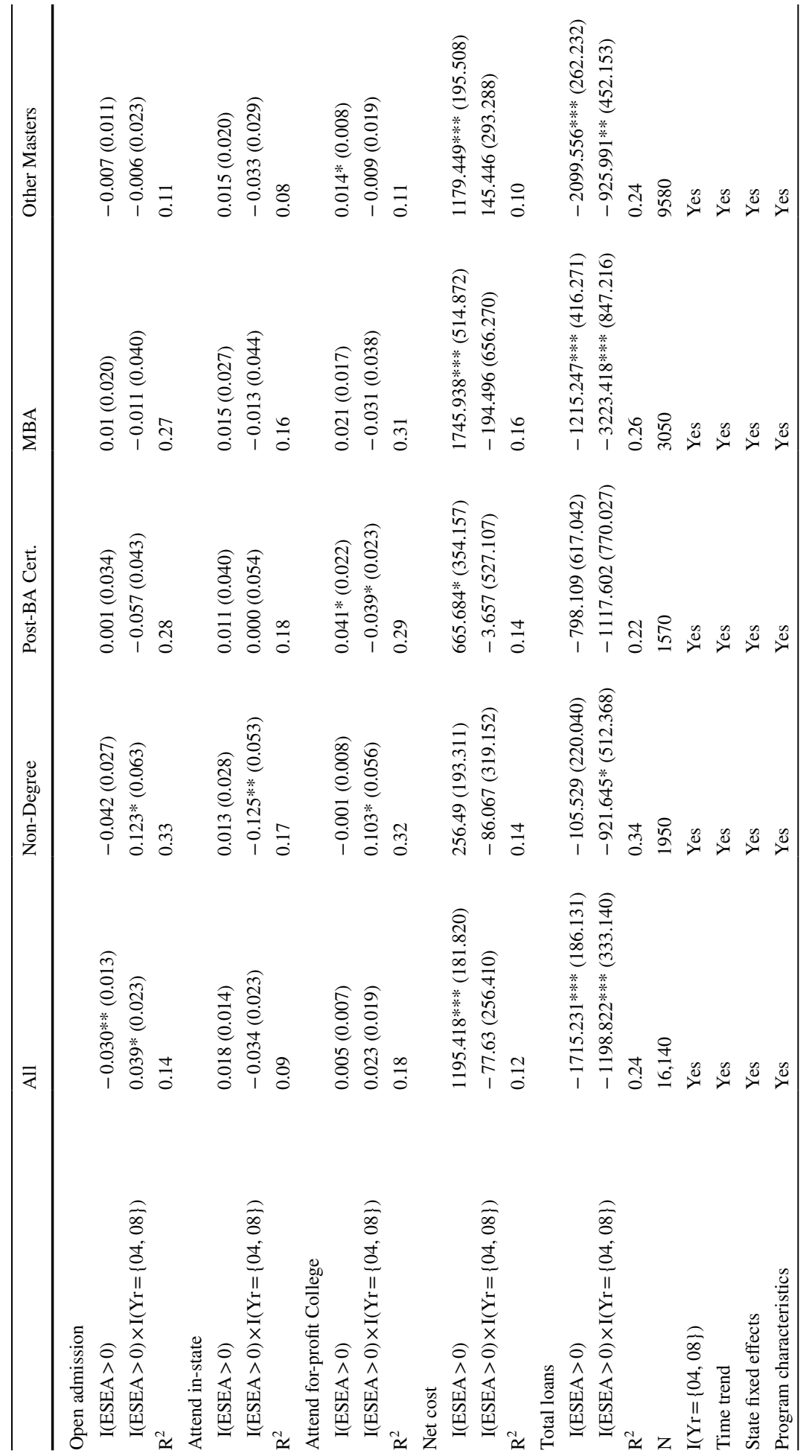




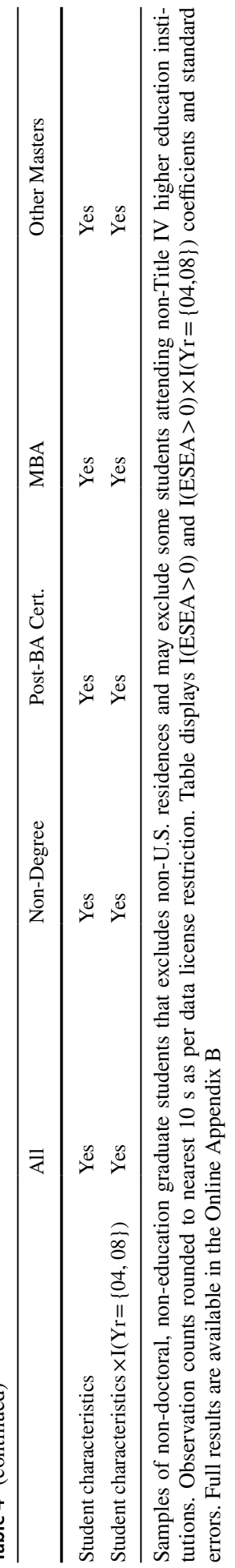

Springer 
benefits decrease by $\$ 922$, on average, in the post-reform period, relative to their pre-law reform peers. Second, post-BA certificate students who exercise ESEA benefits are $4.1 \%$ more likely to attend for-profit colleges and this reduces to approximately zero in the postreform period. The net cost for post-BA students who exercise ESEA benefits is $\$ 666$ higher, and this amount does not change post-law reform. Interestingly, no differences in total annual loans is identified between those that exercise ESEA and those that do not, either before or after the law change for post-BA certificate students. Third, MBA students who exercises ESEA benefits do not attend open admission programs, attend in-state, or attend for-profit colleges any differently than those that do not either before or after the law reform. However, MBA students who exercise ESEA benefits attend programs with higher net costs of $\$ 1746$, and higher cost remains in the post-law reform period. MBA students that exercise ESEA benefits have substantially lower total annual loans of $\$ 1215$, and this declines further by $\$ 3223$ in the post-law reform, relative to their pre-law reform peers. Fourth, non-education, non-MBA master's students that exercise ESEA benefits are $1.4 \%$ more likely to attend for-profit colleges, have net costs that are $\$ 1179$ higher, and total annual loans that are $\$ 2100$ lower, relative to their non-ESEA exercising peers. No differentials are identified between those that exercise ESEA and those that do not with respect to the propensity to attend open admission or in-state programs in either the pre- or post-law reform periods. Additionally, neither the rates of for-profit college attendance nor net costs change post-law reform for non-education, non-MBA master's students; however, total annual loans decrease by an additional $\$ 926$ for those that exercise ESEA benefits, relative to their pre-law reform peers.

These results suggest that the largest differences in educational outcomes due to ESEA use are identified for students who are non-degree seeking and post-BA certificates. With respect to cost and finance, students that are non-degree seeking or attending master's programs (both MBA and non-educational, non-MBA master's) who exercise ESEA have larger differences in the pre- and post-reform periods relative to their peers. To understand the size of the above magnitudes, the average net cost for non-degree seeking students is \$1491, MBA students is \$4387, and non-MBA, non-education master's students is \$2628. Thus, the reductions in net costs by those that exercise ESEA benefits in the post period (\$1828 for non-degree seeking students, \$4143 for MBA students, and \$2881 for other master's degree students) suggest that the law reform had substantial impacts on students' educational finance.

As discussed above, we validate assumptions of the difference-in-difference specification in three ways and present the results of these tests in Table A.3 and B.1. We present evidence on the robustness of the results by incrementally introducing control variables and demonstrating coefficient stability in Table B.1 (with all other falsification and robustness analyses included in Table A.3). By progressively including more variables on the right-hand side, we demonstrate that coefficients appear quite stable and those that are significant in the baseline model remain significant throughout all models. As discussed above, the largest difference in the impact of ESEA on educational outcomes is, unsurprisingly, when student characteristics are included and that student compositional changes post-law reform do not impact the causal inference of the law reform. Second, moving the law from 2001 back in time so that the 1999-2000 graduate student cohort is impacted by the law erroneously suggests that all graduate program selectively outcomes are not impacted post-law reform, suggesting the law impacts do not happen by chance. Third, we drop 270 higher education workers from the sample who apply tuition waivers. The estimated impacts of applying ESEA post-law reform remain quite stable. Fourth, we drop 910 veterans/active military and again report the estimated impacts of applying 
ESEA post-law reform remain stable. Lastly, the results from the PST analysis suggest that removing those most likely and least likely to exercise ESEA does not attenuate the results, but rather strengthens them. The PST drops 6510 students with propensities to exercises ESEA between 0.0 and 0.1 and 0.9 and 1.0 from the sample. The results of the subsampled estimation of Eq. (1) in Table A.3 suggest that even with the removal of this group, the impact of ESEA post-law reform remains quite similar in magnitude. That being said, the PST analysis for those with estimated propensities between $(0.2$ and 0.8$)$ removes 9080 students and the results start to attenuate. ${ }^{17}$ Compared to the baseline results, the PST estimates are slightly smaller. Buddin and Kapur (2005) and Garcia et al. (2002) using similar empirical methodologies estimate the correlation between exercising ESEA benefits and remaining in the U.S. Navy. They find a 16.5 percentage point decline in retention using their baseline model and 7.5 percentage point decline using propensity score matching, suggesting that the propensity score analyses may provide lower estimates than other baseline model estimates (Table A.3).

\section{Results by Gender}

As discussed above, the descriptive statistics suggest males and females have near identical graduate program choice and somewhat different costs and financing. We use a tripledifference empirical analysis to compare the triple interaction between males and females, between those that exercise ESEA benefits and those that do not, and before and after the law change (see Eq. (2) above). The estimates of Eq. (2) are provided in Table 5 for the five educational outcomes for all non-doctoral, non-education graduate students and also by graduate program. Similar to Table 4, the table only includes the coefficient estimates and standard errors on the main variables of interest: $I\left(E S E A_{i s t}>0\right) \times I(Y r=\{04,08\})$ and $I\left(E S E A_{i s t}>0\right) \times I(Y r=\{04,08\}) \times$ Male and the full results are available in Online Appendix B, Table 3.1-3.5. The table also includes the $R^{2}$ from each regression. With five educational outcomes and five different samples of students, Table 5 contains output from 25 regressions.

The results suggest that male and female non-doctoral, non-education graduate students that exercise ESEA benefits have no differences in their rates of attending open-admission graduate programs or attending for-profit colleges pre- or post-law reform. However, there is evidence that female non-doctoral, non-education graduate students that exercise ESEA benefits are $7.2 \%$ less likely to attend in-state post-law reform, relative to females that exercise ESEA benefits pre-law reform. On the other hand, male non-doctoral, non-education graduate students that exercise ESEA benefits are no more likely to attend in-state post-law reform, relative to their pre-law reform peers.

We provide estimates of Eq. (2) by graduate program similar to the main results. First, non-degree seeking female students who exercise ESEA benefits post-reform are $13.9 \%$ more likely to attend an open-admission graduate programs, $16.0 \%$ less likely to attend instate, but no more likely to attend for-profit colleges, relative to their pre-law reform peers. These are very similar to the main results and no program choice impacts are observed for non-degree seeking male graduate students. No impact of exercising ESEA on net cost or total annual loans are identified for either gender post-law reform, relative to their prelaw reform peers. Second, post-BA certificate male students who exercise ESEA benefits

17 All observation counts are rounded to the nearest tens. 


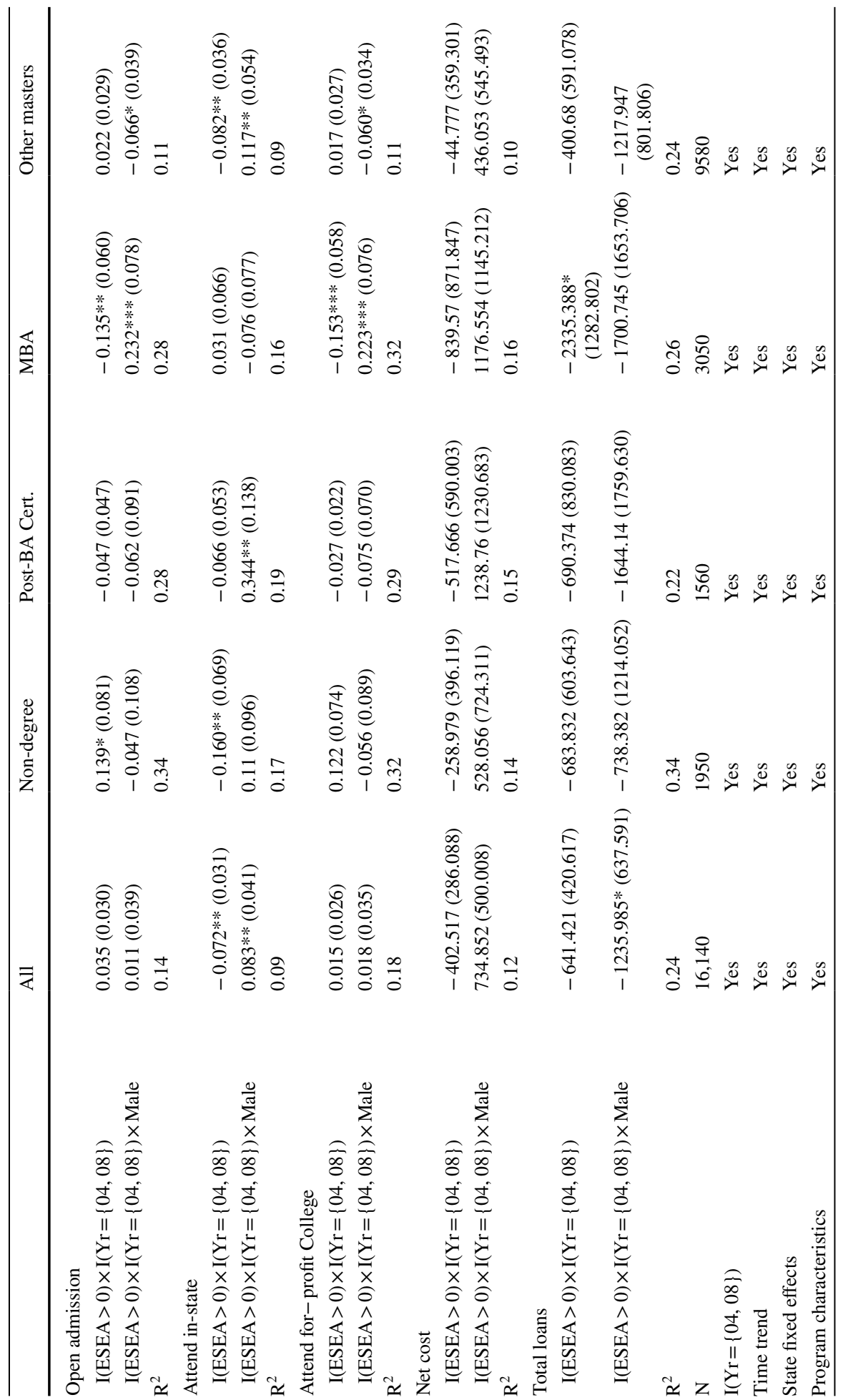




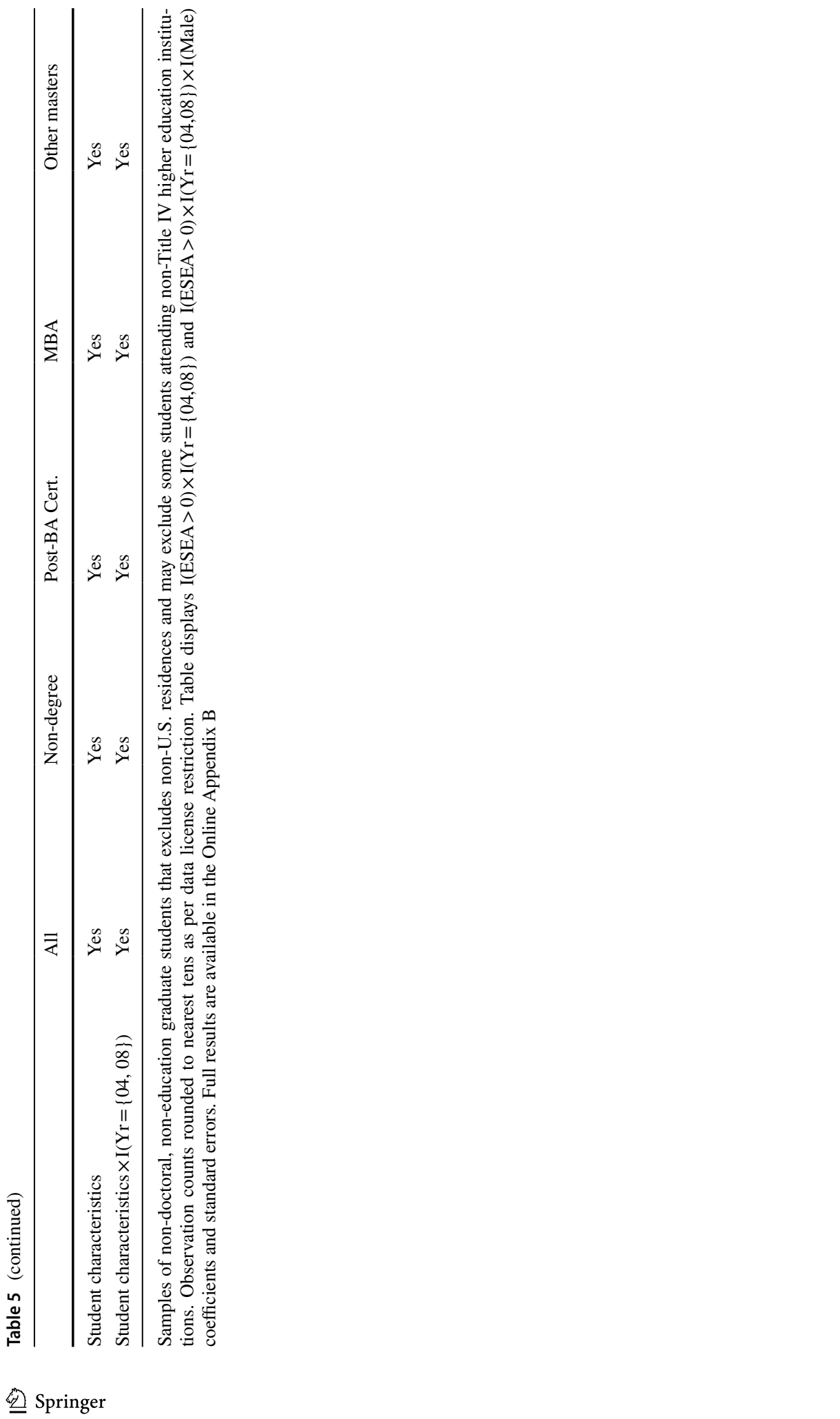




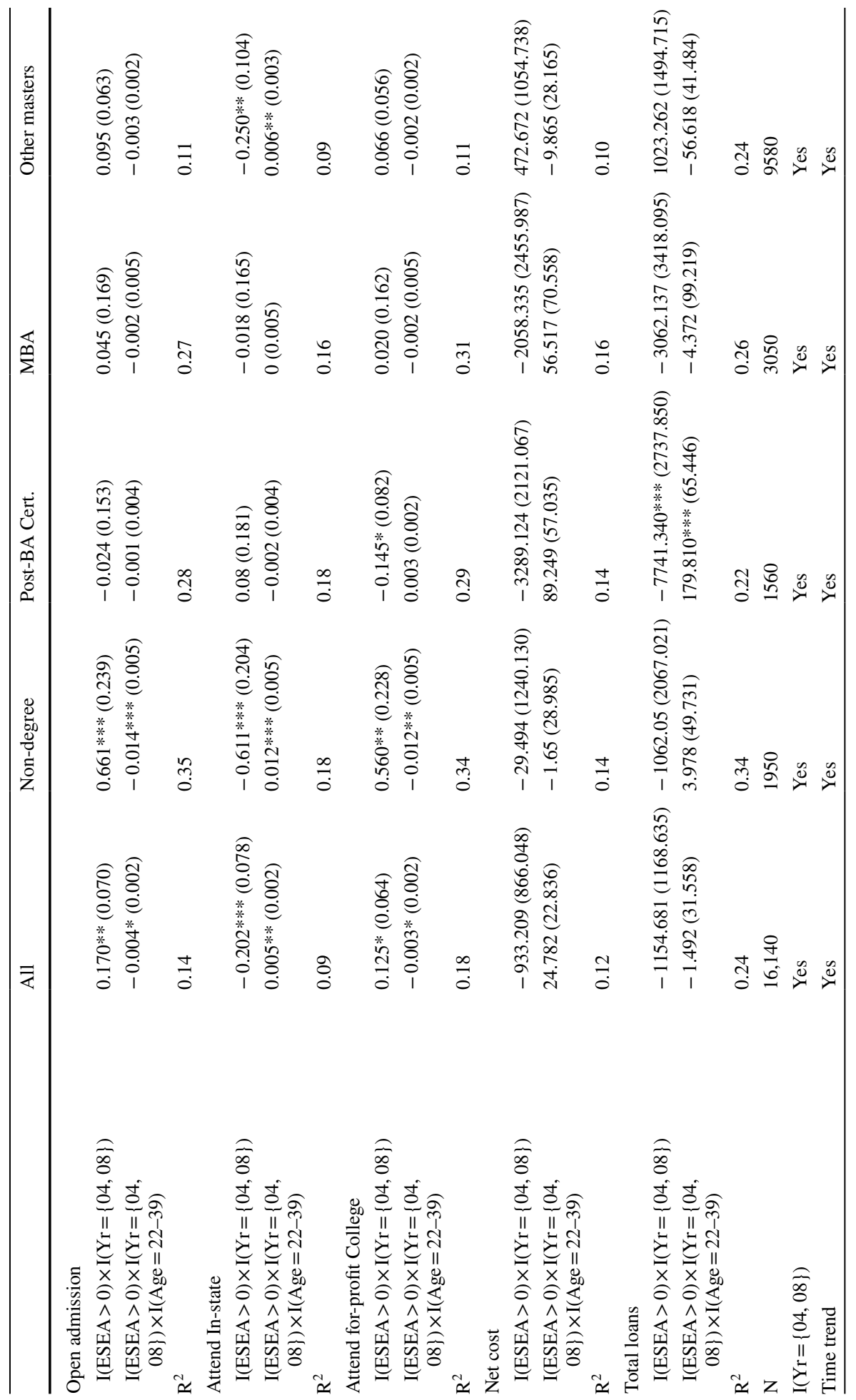




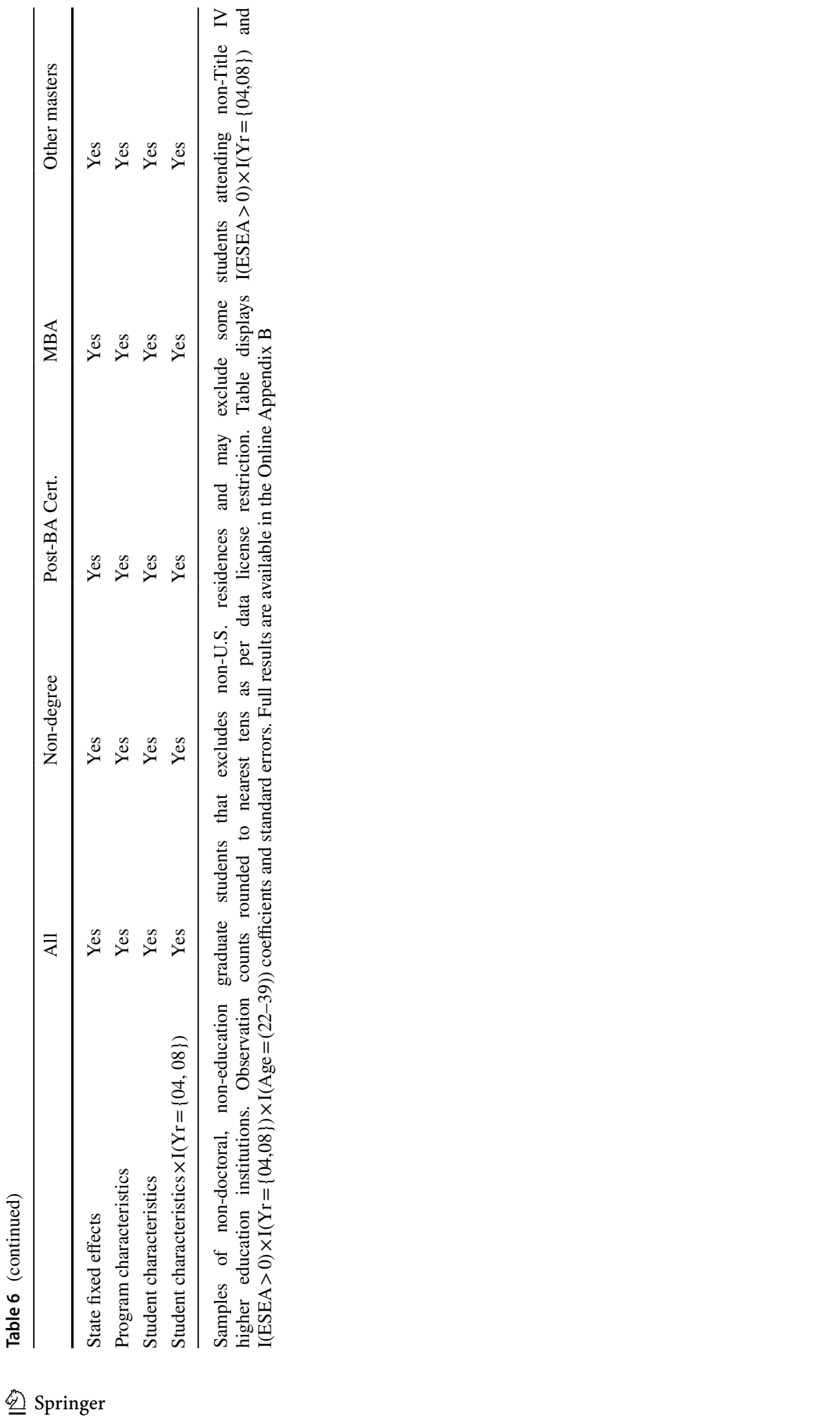


are $3.4 \%$ more likely to attend in-state, relative to their pre-law reform peers, and no differentials are observed with respect to attending an open-admission program or attending for-profit colleges. Third, the results suggest that male MBA students who exercise ESEA benefits post-law reform are more likely to attend open-admission programs and for-profit colleges, relative to female MBA students post-law reform, but net costs remain similar for both male and female MBA students who exercise ESEA benefits post-law reform. The results suggest that female MBA students who exercise ESEA benefits decrease their loan amounts by $\$ 2335$, relative to their pre-law reform peers, while male MBA students who exercises ESEA benefits post-law reform appear to not change their loan balances. Fourth, the results suggest that male non-education, non-MBA master's students who exercise ESEA benefits post-law reform are $6.6 \%$ less likely to attend open-admission programs, $11.7 \%$ more likely to attend in-state, and $6.0 \%$ less likely to attend for-profit colleges, relative to pre-law reform peers. Both net costs and total annual loan amounts remain similar for both male and female MBA students who exercise ESEA benefits post-law reform, relative to their pre-law reform peers.

\section{Results by Age}

We also provide analysis by age that compares the triple interaction between students ages 22-39 and those 40-59, between those that exercise ESEA benefits and those that do not, and before and after the law change (see Eq. (2) above). The estimates of Eq. (2) are provided in Table 6 for the five educational outcomes for all non-doctoral, non-education graduate students and also by graduate program. The table only includes the coefficient estimates and standard errors on the main variables of interest: $I\left(E S E A_{i s t}>0\right) \times I(Y r=\{04,08\})$ and $I\left(E S E A_{i s t}>0\right) \times I(Y r=\{04,08\}) \times I($ Age $=22-39)$. The full results are available in Online Appendix B, Tables 4.1-4.5.

The results suggest that the substantial differences observed in the descriptive statistics remain after controlling for a host of observable characteristics. The estimates suggest that older students that use ESEA post-law reform are $17.0 \%$ more likely to attend an openadmission graduate program, $20.2 \%$ less likely to attend in-state, and $12.5 \%$ more likely to attend for-profit colleges. However, no differences in net cost or total annual loans is observed.

The results by graduate program suggest that the differences observed by age are almost entirely attributable to non-degree seeking graduate students. Additionally, few differences in graduate program choice are identified for post-BA certificate students, MBA students, and other master's degree students for those who exercise ESEA benefits post-law reform. The results also indicate substantial reductions in loan amounts for older workers who exercise ESEA benefits post-law reform and are enrolled in a post-BA certificate.

\section{Conclusion}

In the modern knowledge economy, employers often offer their employees tuition assistance as a fringe benefit to attract and retain higher quality workers and, in turn, increase the human capital of their workforce. One popular avenue for exercising this benefit is to pursue a graduate education. For this benefit to maximize benefits for firms, it is imperative that students select quality programs, and this decision can be significantly affected by the benefits themselves. The empirical results of this paper suggest that non-degree seeking 
graduate students who exercise ESEA benefits post-law reform are more likely to attend open-admission graduate programs, less likely to attend in-state, and more likely to attend for-profit colleges, relative to their pre-law reform peers. The results also suggest that all non-education, non-doctoral graduate students reduce their loan balances significantly post-law reform, but do not change their overall net cost of attendance. Results by graduate program suggest substantial heterogeneity. The most prominent differences are between male and female MBA students who exercise ESEA post-law reform. Additionally, results by age suggest that older workers that exercise ESEA benefits are much more like to attend programs that are open-admission, out-of-state, and offered by for-profit colleges, than their pre-law reform peers.

While this research cannot uncover whether the increase is attributable due to increases in eligibility or increases in participation, these results are important and provide some insight into how ESEA benefits impact graduate education choice and finance. Our research suggests firms should consider that the structure of higher education has changed over the last 15 years with the advent of the internet to evaluate whether they still receive the return that is anticipated from past cohorts. It is also important to note that ESEA has had the effect of drawing more people into obtaining graduate degrees who otherwise wouldn't have. Important future research includes whether the observed changes are attributable to more firms offering ESEA benefits or due to more workers taking advantage of better ESEA programs. Another important topic is the impact of exercising ESEA benefits on workers' lifetime productivity and earnings.

Acknowledgements We would like to thank seminar participants at the American Education and Finance Policy Annual Conference (2016), Western Economic Association International Conference (2016), and Southern Economic Association (2016), the editor and two anonymous referees for suggestions that greatly improved this research. The views expressed herein are those of the authors and do not reflect the position of the United States Military Academy, the Department of the Army, or the Department of Defense.

\section{References}

Alon, S. (2007). The influence of financial aid in leveling group differences in graduating from elite institutions. Economics of Education Review, 26(3), 296-311.

Altonji, J., Arcidiacono, P. \& Maurel, A. 2015. The analysis of field choice in college and graduate school: Determinants and wage effects. NBER Working Paper 21655.

Arcidiacono, P., Cooley, J., \& Hussey, A. (2008). The economic returns to an MBA. International Economic Review, 49(3), 873-899.

Armona, L., Chakrabarti, R. \& Lovenheim, M. 2018. How does for-profit college attendance affect student loans, defaults, and labor market outcomes? NBER Working Group 25042.

Avery, C., \& Hoxby, C. (2004). Do and should financial aid packages affect students' college choices? In C. Hoxby (Ed.), College choices: the economics of where to go, when to go, and how to pay for it (pp. 239-302). Chicago: University of Chicago Press.

Bacolod, M., \& Chaudhary, L. (2018). Distance to promotion: evidence from military graduate education. Contemporary Economic Policy, 36(4), 667-677.

Becker, G. S. (1965). Human capital. Chicago, IL: University of Chicago Press.

Bedard, K., \& Herman, D. (2008). Who goes to graduate/professional school? The importance of economic fluctuations, undergraduate field, and ability. Economics of Education Review, 27(2), 197-210.

Bettinger, E. (2004). How Financial Aid affects Persistence. In C. Hoxby (Ed.), College choices: The economics of where to go, when to go, and how to pay for it (pp. 239-302). Chicago: University of Chicago Press.

Bruce, D., \& Carruthers, C. (2014). Jackpot? The impact of lottery scholarships on enrollment in Tennessee. Journal of Urban Economics, 81, 30-44.

Buddin, R., \& Kapur, K. (2005). The effect of employer-sponsored education on job mobility: Evidence from the U.S. Navy. Industrial Relations: A Journal of Economy and Society, 44(2), 341-363. 
Cellini, S., Darolia, R., \& Turner, L. (2018). Where do students go when for-profit colleges lose federal aid. NBER Working Paper 22967.

Cellini, S., \& Goldin, C. (2014). Does federal student aid raise tuition? New evidence on for-profit colleges. American Economic Journal: Economic Policy, 6(4), 174-206.

Cornwell, C., Mustard, D., \& Sridhar, D. (2006). The enrollment effects of merit-based financial aid: Evidence from Georgia's HOPE Program. Journal of Labor Economics, 24(4), 761-786.

Crump, R., Hotz, V., Imbens, G., \& Minik, O. (2009). Dealing with limited overlap in estimation of average treatment effects. Biometrika, 96(1), 187-199.

Dale-Olsen, H. (2006). Wages, fringe benefits and worker turnover. Labour Economics, 13(1), 87-105.

Darolia, R., Koedel, C., Martorell, P., Wilson, K., \& Perez-Arce, F. (2015). Do employers prefer workers who attend for-profit colleges? Evidence from a field experiment. Journal of Policy Analysis and Management, 34, 881-903.

Declercq, K., \& Verboven, F. (2018). Enrollment and degree completion in higher education without admission standards. Economics of Education Review, 66, 223-244.

Deming, D., Goldin, C., \& Katz, L. (2012). The for-profit postsecondary school sector: Nimble critters or agile predators? Journal of Economic Perspectives, 26(1), 139-164.

Deming, D., Yuchtman, N., Abulafi, A., Goldin, C., \& Katz, L. (2016). The value of postsecondary credentials in the labor market: An experimental study. American Economic Review, 106(3), 778-806.

Denning, J. (2018). Born under a lucky star: Financial aid, college completion, labor supply, and credit constraints. Journal of Human Resources. https://doi.org/10.3368/jhr.54.3.1116.8359R1.

Denning, J., \& Turley, P. (2017). Was that SMART? Institutional financial incentives and field of study. Journal of Human Resources, 52(1), 152-186.

Dynarski, S. (2003). Does aid matter? Measuring the effect of student aid on college attendance and completion. American Economic Review, 93(1), 279-288.

Eide, E., Hilmer, M., \& Showalter, M. (2016). Is it where you go or what you study? The relative influence of college selectivity and college major on earnings. Contemporary Economic Policy, 34, 37-46.

Elliott, C., \& Soo, K. (2013). The International Market for MBA qualifications: The relationship between tuition fees and applications. Economics of Education Review, 34, 162-174.

Field, E. (2009). Educational debt burden and career choice: Evidence from a financial aid experiment at NYU Law School. American Economic Journal: Applied Economics, 1(1), 1-21.

Flaherty, C. (2008). The effect of tuition reimbursement on turnover: A case study analysis. In S. Bender, J. Lane, K. L. Shaw, F. Andersson, \& T. V. Wachter (Eds.), The analysis of firms and employees: Quantitative and qualitative approaches. Chicago: University of Chicago Press.

Garcia, F., Arkes, J., \& Trost, R. (2002). Does employer-financed general training pay? Evidence from the US Navy. Economics of Education Review, 21(1), 19-27.

Gicheva, D. (2012). Worker mobility, employer-provided general training, and the choice of graduate education. Labour Economics, 19(2), 232-240.

Gilpin, G., Saunders, J., \& Stoddard, C. (2015). Why has for-profit colleges' share of higher education expanded so rapidly? Estimating the responsiveness to labor market changes. Economics of Education Review, 45, 53-63.

Hussey, A. (2012). Human capital augmentation versus the signaling value of MBA education. Economics of Education Review, 31(4), 442-451.

Jaeger, D., Joyce, T., \& Kaestner, R. (2018). A cautionary tale of evaluating identifying assumptions: Did reality TV really cause a decline in teenage childbearing? NBER Working Paper 24856.

Joint Committee on Taxation, Estimate of Federal Tax Expenditures for Fiscal Years 2007-2011, JCS-3-07, 2007.

Jones, G., Coulombe, K., Stohler, T., \& Harris, S. (2010). Who benefits from Section 127? National Association of Independent Colleges and Universities Working Paper.

Kinser, K. (2006). From main street to wall street: The transformation of for-profit higher education. San Francisco: Jossey-Bass.

Kofoed, M. 2015. For-profit and traditional colleges: institutional aid and financial aid allocation. Working Paper.

Lang, K., \& Weinstein, R. (2013). The wage effects of not-for-profit and for-profit certifications: better data, somewhat different results. Labour Economics, 24, 230-243.

Lerman, R., McKernan, S., \& Riegg, S. (2004). The scope of employer-provided training in the United States: Who, what, where, and how much? In C. J. O’Leary, R. A. Straits, \& S. A. Wandner (Eds.), Job training policy in the United States. Kalamazoo: W.E. Upjohn Institute for Employment research.

Lovenheim, Michael F., \& Owens, Emily G. (2014). Does federal financial aid affect college enrollment? Evidence from drug offenders and the Higher Education Act of 1998. Journal of Urban Economics, $81,1-13$. 
Manchester, C. (2010). Investment in general human capital and turnover intention. American Economic Review: Papers and Proceedings, 100(2), 209-213.

Mehay, S., \& Pema, E. (2010). Analysis of the Tuition Assistance Program: Does the method of instruction matter in TA classes?. Naval Postgraduate School: Technical report.

Montgomery, M. (2002). A nested logit model of the choice of a graduate business school. Economics of Education Review, 21(5), 471-480.

Neal, D. (1995). Industry-specific human capital: Evidence from displaced workers. Journal of Labor Economics, 13(4), 653-677.

Rosenbaum, P., \& Rubin, D. (1983). The central role of the propensity score in observational studies for causal effects. Biometrika, 70(1), 41-55.

Tran, H., \& Smith, D. (2017). The impact of employer-sponsored educational assistance benefits on community college student outcomes. Journal of Student Financial Aid, 47(2), 83-100.

Turner, L. (2014). The road to pell is paved with good intentions: The economic incidence of federal student grant aid." Working Paper.

van der Klaauw, W. (2002). Estimating the effect of financial aid offers on college enrollment: A regressiondiscontinuity approach. International Economic Review, 43(9), 1249-1287.

Publisher's Note Springer Nature remains neutral with regard to jurisdictional claims in published maps and institutional affiliations. 